\title{
J.L.L. Aranguren: reformador moral en época de crisis
}

\author{
PEDRO CEREZO \\ Universidad de Granada
}

En el doble tono del pensamiento de Aranguren -el del filósofo moral y el de moralista - es el segundo el que lleva el cantus fimus y constituye el estilo del pensador. En este sentido, la obra de J.L. Aranguren continúa creadoramente la gran tradición moralista del pensamiento hispánico. Remedando la expresión orteguiana, podría definirse como «experimentos morales de nueva España», poniéndola en forma moral. A la vez, pervive en ella el aliento unamuniano de una profunda reforma del ethos del catolicismo español. Pero J.L. Aranguren ha realizado su vocación de reformador moral en un ejercicio de transmutación íntima, de autodesprendimiento irónico y transcendimiento utópico del propio $s \hat{t}$ mismo. En otros términos: ha llevado a cabo su tarea de reformador en la tensión entre el desbloqueo crítico de la experiencia moral y su apertura hacia un nuevo horizonte. En un primer momento, el ámbito de experimentación estuvo demarcado por el «buen talante» católico y una metafísica intelectualista zubiriana, que fraguaron en una ética normativa, abierta a las diferentes esferas de la cul- tura y de profunda inspiración religiosa. Posteriormente, la exploración de la crisis nihilista de Occidente produjo una profunda inflexión en su planteamiento. La crisis determinó un arepliegue ético» decisivo, es decir, una mayor vecindad al planteamiento kantiano, poniendo ahora el acento en la actitud o existencia ética en sí misma, por encima de los contenidos. En sustitución del estilo fundamentalista de la metafísica, el factum moral y el mundo de la vida son ahora los dos focos de constitución de la experiencia moral. Paralelamente, la tarea del reformador moral se centra en el sondeo de la desmoralización utópica de la existencia. La crítica se ejerce fragmentariamente, a piezas sueltas, en torno a los problemas más acuciantes de la experiencia moral: violencia, consumismo, marginación social, tecnificación burocrática de la moral, establecimiento democrático, etc. Acorde con este reforzamiento de la actitud ética se agudiza la tensión entre ética y política hasta límites trágicos, a la par que se replantea sobre nuevas bases la relación entre una moral utópica, de tensión y aspiración, y una religión abierta.

\section{Entre la ironia y la utopia}

Al igual que hay un estilo literario, y un estilo existencial, hay también un estilo mental, una forma original y propia, poética o creadora, pues «todo estilo es poético» ${ }^{1}$ - aseguraba Unamuno- al vivir y obrar el pen- 
samiento, de conducir y conformar la vida intelectual. En él reside la individualidad del pensador, de modo que temas y problemas, intereses e ideas permanecen como en estado de suspensión hasta no encontrar la fragua mental estilística en que son acuñados. Captar el estilo es la culminación de la faena interpretativa, pues la comprensión del sentido de un mundo es inescindible de la figura estilística en que se ha fraguado, $o$ por volver de nuevo al maestro Unamuno, es siempre un mundo hecho hombre. ${ }^{2}$ Creo que la forma mentis arangureniana está más próxima al moralista que al filósofo moral, y aun dentro de aquél, más cercana a los moralistas, no de plática y oficio, moralistas legisladores, sino de ejercicio de íntima transmutación. Es bien sabido que toda reflexión moral genuina se debe a una moral vivida, que la precede y la envuelve, y a la que trata de esclarecer críticamente, con vistas - según los casos- a su confirmación o superación. Pero esto no basta: esta moral vivida, compartida, en la que ya se está, puede no haber llegado a ser auténtica experiencia moral, un campo propio e íntimo de experimentación del yo práctico, que, por así decirlo, se pone a prueba a sí mismo en su ethos o individualidad. La reflexión es entonces, en verdad, un momento interior a la experiencia, que la esclarece y potencia y hasta logra transmutarla. Es éste un circuito interior de la libertad como vida en reflexión, o, dicho a la inversa, como reflexión implantada en la existencia. En esta simbiosis de reflexión y experiencia moral, de autojuicio y experimentación, consiste el estilo mental de José Luis L. Aranguren. El circuito de moral vivida y moral pensada nunca se cierra; se mantiene siempre en tensión, siempre abierto y alerta, como el movimiento de la libertad.

De ahí que encuentre un tanto artificioso el esquema evolutivo de su pensamiento propuesto por Enrique Bonete, de la moral vivida (primera época) a la filosofía moral (segunda) y retorno de nuevo (tercera época) a la moral vivida, aunque el propio Bonete mitiga en cierto modo su tesis al reconocer que el método de Aranguren «se levanta [...] sobre las experiencias morales». ${ }^{3}$ De hecho, este circuito ha estado presente en todo momento. No hay duda que Catolicismo y protestantismo como formas de existencia (1952) y El protestantismo y la moral (1954), que enlazan con la experiencia vivida de Catolicismo día tras día (1955), encierran una amplia reflexión a nivel ético sobre un eje básico del pensamiento moral aranguriano, la tensión entre moral y religión y la correspondencia de la diversidad de talantes con formas de la experiencia moral/religiosa. Pero, recíprocamente, Ética (1958) y Ética y Politica (1963) —sus dos obras mayores de Filosofía moral-contienen un rico y pregnante trasfondo de moral vivida - moral de inspiración religiosa, cifrada en un catolicismo abierto y liberal, y moral política respectivamente, muy expresa ésta segunda en la relación dramática, tensa y ardua, entre la ética y la política. 
Es muy significativo, por otra parte, que los años académicos de J.L. Aranguren, del cincuenta y cinco al sesenta y cinco, en los que desarrolla el mayor volumen de filosofia moral, sean también los de su compromiso ćtico/civil, que lo llevan a la pérdida de su cátedra y al autoexilio, y todos los que tuvimos la suerte de tratarlo asiduamente por aquel tiempo podemos dar fe de la riqueza y vitalidad de su experiencia moral. Los seminarios de aquellos años, y muy especialmente el seminario Eugenio d'Ors, son prueba elocuente de la importancia de la moral vivida en sus enseñanzas. Y otro tanto ocurre a partir de Moralidades de hoy y de mañana (1973) - obra característica, hasta en el título, de la tercera etapa- en la que es fácil reconocer como en otras de este último período, como dibujada en puntos suspensivos, la línea implícita de una distribución de su biografía en tres etapas, en las que primaría respectivamente, como cree J.L. Abellán, la acción religiosa de signo católico, la acción intelectual y la acción moral. ${ }^{4}$ En primer lugar, porque la reflexión de carácter moral ha sido siempre el hilo directivo de su obra; pero, de otra parte, la reflexión moral/religiosa de primera hora no estaba ayuna de intencionalidad política, en la medida en que abogaba por un catolicismo emancipado del enfeudamiento político de la jerarquía, y que pudiera evitar la extensión a la esfera de la religión del conservadurismo político, es decir, «a primacía absoluta otorgada al mantenimiento del orden y la seguridad. ${ }^{5}$ La liberación de la sensibilidad y el pensamiento religiosos y el ejercicio del derecho a pensar por cuenta propia en un ambiente sociocultural sofocantemente eclesiástico ${ }^{6}$ representaban en aquellas circunstancias una contribución decisiva, aunque oblicua o indirecta, a la crítica política al régimen confesional. $\mathrm{E}$ inversamente, la reflexión moral/política de los años setenta y cinco en adelante sigue estando sostenida por una profunda inspiración religiosa. Sería, por tanto, más justo hablar, como ha hecho Norbert Bilbeny en las páginas de El Cievo, de alos dos tonos de una misma voz, el del filósofo moral y del moralista», ${ }^{7}$ aunque, a mi juicio, el cantus firmus lo lleva la experiencia moral, que sostiene a la otra voz, apoyada, de la reflexión ético-filosófica.

Pero esto quiere decir que J.L. Aranguren, antes que filósofo moral -en un "antes", claro está, no cronológico, sino existencial-, ha sido reformador moral; incluso su propia ética teórica, con aportaciones tan decisivas como el ethos o el carácter, el talante y la vocación, y su ćnfasis en la unidad y continuidad de la vida moral como un todo, sólo se dibuja en su auténtico relieve a la luz de la experiencia moral y el impulso reformador, que le subyace. ¿Qué significan, por ejemplo, las «aperturas» (o subalternancias) de la ética a la psicología, la sociología, la religión o la metafísica, sino el afân de recoger la experiencia moral en todos sus registros y en los contextos efectivos de condicionamiento, en que opera?: 
Este libro, por ser filosófico, es de moral pensada -declara al comienzo de la Ética-. Sin embargo, he procurado mantenerlo siempre muy abierto a la moral vivida, religiosa o secularizada, minoritaria o social, personal o usual. Creo que este "empirismos, sobre todo si se conjuga con el principal de una fundamentación antropológica y psicológica positiva, es de una importancia capital, ${ }^{8}$

Y, a punto de cerrar la obra, en unas consideraciones finales sobre el método, vuelve a la intuición directriz:

Me parece que la solución está en la atención a la realidad, es decir, la experiencia, a la vida, a la historia, a la religión, y, en fin, a la literatura como expresión de todo esto. Lo cual de ninguna manera es una "concesión», pues, como hemos visto a lo largo de este libro, de todo ello y no de abstracciones tiene que alimentarse la ética. ${ }^{9}$

¿Quién que haya asistido a las clases y seminarios de Aranguren no recuerda con emoción la impresión viva, directa, de una reflexión ejemplar en su finura y rigor, que sondeaba todos los registros de la experiencia, buscando la integridad de su sentido? ¿Quién no pondría, incluso por encima de sus enseñanzas, la viva lección de humanidad, de sensibilidad y juicio, de buen talante moral y cívico, que trascendía de su trato...? En otra ocasión he insinuado que J.L. Aranguren prolonga la rica y noble tradición del pensamiento moralista español. No sorprende, pues, la afinidad de su actitud, ya que no de talante, con la del reformador religioso que fue fundamentalmente, Miguel de Unamuno -el «evangelio quijotesco de la libertad» como fermento de un nuevo ethos civil-, y la del reformador cultural, Ortega y Gasset, empeñado en experimentos de una nueva España. Una y otra reforma acaban desembocando en la reforma moral. Pero en el caso de Aranguren, ésta ocupa el primer plano de su atención, porque, al cabo, lo único de lo que el hombre es plenamente responsable es del sentido de su vida. Aunque de inspiración también religiosa y de inequívoca trascendencia sociocultural, la reforma emprendida por Aranguren concierne, en primera instancia, a la actitud ética, a los modos personales y sociales de comportamiento; en definitiva, a la experiencia moral de su pueblo, de su tiempo y su circunstancia -tres fidelidades a las que nunca renuncia-, intentando esclarecerla y promoverla hacia mayores cotas de libertad.

Empleo aquí la expresión "reformador moral», esquivando la más gastada de "moralista" y la más neutra, aun siendo su preferida, de «intelectual». Se trata de una vocación educadora que no puede ejercerse sin el testimonio de la propia vida. El reformador moral se embarca en una aventura de autoexperimentación en un doble frente: crítica, por un lado, de las costumbres y formas de vida vigentes, y en las que él mismo se encuentra implicado, y apertura, por otro, de un nuevo horizonte mo- 
ral. Se comprende que acontezca entre la ironía y la utopía, la tensiớn interna constitutiva del espíritu de creación. Ya Eugenio d'Ors, a quien Aranguren dedicó su primer trabajo, había indicado que la cultura es esencialmente ironía, no sólo con respecto a la naturaleza, como pensó Renán, sino consigo misma, tratando de esquivarse en el instante mismo en que amenaza su obliteración; en suma, "adhesión a medias», ${ }^{10}$ es decir, en vuelo y desprendimiento, en que consiste la verdadera posición de libertad. Ortega, por su parte, había mostrado la dimensión utópica específica de la condición humana, siempre más allá de sí misma de lo que en cada caso es, en un anticipo constante de su ser. La unidad dialéctica de ambas dimensiones origina el espacio angosto de creatividad, de que es capaz el hombre. Y puesto que la élica es la creación que más importa, pues tiene que ver con la obra inacabable de dar sentido y figura moral, ésto es, ethos, a la propia vida, este des-asimiento y trascendimiento han de ser interiores y ejecutados en vivo, en un íntimo experimento. El moralista no puede des-entenderse. Se siente concernido por la experiencia moral que critica, y a la que quiere autentificar, y si fuera el caso, trascender. De ahí que su "crítica» se lleve a cabo en el ejercicio de autodesprendimiento interior, propio de la ironía, y la sapertura de horizonte» en el adelantamiento de sí mismo, en permanente transmutación. No se ha solido reparar en que la crítica aranguriana nunca es externa, como si el asunto no fuera con él. Se ejercita compartiendo una situación, que se ha experimentado en su insuficiencia y limitación, y abriéndola desde dentro de sí misma hacia nuevos horizontes. Ya se trate del catolicismo establecido, al que hay que liberar de su enfeudamiento, o de la democracia establecida, a la que hay que despertar de su letargo, o de la cultura establecida, insensible a las nuevas exigencias, o de la moral, igualmente establecida, del consumismo, al que hay que saber resistirse con un nuevo ideal, sencillo e íntimo de felicidad...; siempre lo establecido es aquello en lo que se encuentra uno instalado, y de lo que sólo puede desprenderse en la renuncia y la aspiración. La actitud crítica aranguriana presenta innumerables registros: a veces es desenmascaramiento, o vuelta del revés, o simplemente relativización lúdica; otras, distanciamiento y hasta desdén, ${ }^{11}$ pero yo prefiero llamarle sencillamente aironía" por la continua referencia a sí mismo y la implicación con aquello que hay que sobrepasar. Y junto a la ironía, la utopía, no como exigencia abstracta ideal, sino como pretensión y gesto, consumando así el movimiento de autoliberación. Si bien se repara, Aranguren no ha brindado tanto ideales de vida cuanto caminos de experiencia, rutas interiores que él mismo ha explorado antes, y de las que, más que una "guia», quiere dejar un sencillo testimonio. En sus constantes reflexiones sobre la figura del «intelectual» —otro nombre para el gastado de "moralista"-, Aranguren ha insistido en la unidad interna de esta 
doble dimensión: trans-gresiva y pro-gresiva a un tiempo, subversiva, si llega el caso, e innovadora; en definitiva, crítica y utópica de modo inescindible:

La desviación y la transgresión, la violación y la infracción conducen $o$, mejor dicho, son ya el inicio de una búsqueda moral que, por su esencia misma, no puede nunca "establecerse". ${ }^{12}$

Puesto en otra clave, la literaria, a la que es tan proclive Aranguren -y posible, además, por la conjunción existencial de lo ético y lo poético en su obra-, la creación genuina ha de ser a la vez subversión e innovación, trasvase metafórico en que se anulan las referencias inmediatas para abrirse a nuevas formas de mundo:

La literatura verdaderamente creadora es en sí misma revolucionaria, desvelación y revelación de la realidad. Hay comunicación franca de la rebeldía literaria a la psíquica, social y moral, y también viceversa. Si la esencia del estilo es desviación -desviación organizándose- es también voluntad de cambio social, motor del cambio moral. ${ }^{13}$

De ahí que el estilo de Aranguren, el mental y el literario, y hasta el existencial, sea el "mixto demoniaco" (en la acepción platónica del término) de la distancia y la búsqueda, en la frontera siempre de dos mundos, simbólicamente abierto, fragmentario e inagotable.

\section{La experiencia de la crisis}

Si en esta fidelidad a la propia vocación cabe hablar de evolución, ésta tiene que afectar a la función crítico/utópica. Quiero decir, un reformador moral no puede conducirse del mismo modo en tiempo de estabilidad que en el de crisis. La conciencia de ésta traza, a mi juicio, una divisoria en la obra de Aranguren, que se acusa tanto a nivel de experiencia como al de reflexión. Con la crisis, no me refiero, claro está, a una de carácter personal, aunque también lo fuera en una medida imponderable, sino a la crisis sustantiva de Occidente, que afecta tanto al sistema de creencias como a los modelos teóricos y códigos de valores. Sería erróneo minimizar el alcance de esta crisis en el pensamiento de Aranguren, aparte de que no haría justicia a su sensibilidad, siempre alerta, y a su sentido de la responsabilidad intelectual. Para un autor tan abierto a la experiencia de la vida y de tan profunda inspiración ético/religiosa es obvio que la pleamar de una crisis tan decisiva no podía dejar de hacer mella en sus planteamientos. Hablando propiamente, se trata de la crisis del nihilismo, que ya había profetizado Nietzsche y sobre la 
que tanto y tan rigurosamente ha meditado Heidegger, autor este último con el que se encuentra familiarizado Aranguren desde sus primeros escritos. Un barrunto de la crisis está ya apuntando en la temprana fecha de Catolicismo día tras día. Allí escribe con resolución:

Pero quien en este confuso mundo de hoy se proponga dedicarse a pensar, debe empezar prudentemente por medir el nivel espiritual de nuestra situación que, muy perentoriamente, puede resumirse así: todas las anteriores seguridades, lo mismo las religiosas que las extrarreligiosas, están hoy puestas en cuestión. Y a continuación debe elegir entre estas dos posibilidades: permanecer bien envuelto en el amparo tradicional o afrontar resueltamente el peligro. Porque de lo que no cabe duda es de la existencia de éste. ${ }^{14}$

Incluso cabe pensar que el aggiomamiento de su catolicismo, poniéndolo al día y a la altura de las circunstancias, representaba un primer esfuerzo por afrontar la crisis, que ya se veía venir:

Nosotros estamos seguros, por el contrario, de que Dios no se ha podido "quedar atrás". Por eso solamente le buscaremos hic et nunc, entre nosotros, en nuestra hora. ${ }^{15}$

Pero la pregnancia del mundo católico, en que se encontraba por entonces inmerso - nunca instalado, y menos de parte del catolicismo oficial-, y el ceñidor metafísico/teológico, básicamente tomista/zubiriano, que faja su experiencia, son tan recios y poderosos que no le dejan ver, en la reducida circunstancia española, el rigor de la crisis. Es verdad que Aranguren descubre la interna heterogeneidad de los talantes de la cultura católica, se enfrenta con el tema del ateísmo ético, frecuenta una filosofía como la existencial, de la que dirá más tarde que es un exponente de la crisis, se abre seria, responsablemente, a la cultura protestante y a las corrientes fundamentales del pensamiento contemporáneo, pero su obra se inscribe, con un buen talante de mesura y equilibrio, en una experiencia existencial religiosa, de signo católico, que lo pone al abrigo de cualquier riesgo. En la misma página en que se refiere al "peligron, puede escribir con resolución animosa y militante:

No es cómoda, no, nuestra situación, pero hay que hacerle frente. Pongamos, pues, juntos en nuestro corazón, el animosa firmat fides y el animosus firmat intellectus y echemos a andar hacia adelante..$^{16}$

De ahí que la doble vertiente —crítica y utópica- del reformador moral no pueda tener el mismo alcance en este mundo abrigado que en las etapas posteriores. Tanto la inspiración crítica como la apertura utópica se mantienen dentro de los límites de este universo cultural. Frente 
al catolicismo oficial, integrista y dogmático, puesto «al servicio del Sisteman, Aranguren se esfuerza por la autentificación y liberalización de la cultura católica en un sentido secular y civil, desamortizándola, como había dicho Unamuno, de las instancias del poder eclesiástico, y situándola en la frontera de los problemas del mundo contemporáneo, sin recelos ni inhibiciones. Así, por ejemplo, advierte de los graves estragos que una religiosidad pública puede ocasionar al «fuero interno", es decir, a una moral reflexiva y una experiencia personal de la fe. ${ }^{17}$ No es todavía, ciertamente, la obra de un heterodoxo, pero sí la de un católico liberal, cosa que al viejo Unamuno le sonaba a contradicción en la España de su tiempo. Al menos se había superado el "alma trágica» y un nuevo talante de mesura y confianza, y hasta un nuevo ethos, armónico e integracionista, ecuménico de intención y actitud, comenzaba a abrirse camino. La crítica literaria de este período recogida en Critica y Meditación (1957) se complace igualmente en señalar la experiencia ético/religiosa de la generación poética del 36 -Vivanco, Panero, Rosales y el joven José María Valverde - con la conjunción de poesía y existencia, creación y vida personal, tan decisiva en su propio pensamiento ético:

Existencia poética —escribía al filo de Rilke-significa poesía hecha categoría existencial, nervio y entraña de la vida. ${ }^{18}$

Y la filosofía no podía menos de acudir también solícita a esta cita de lo ético y lo poético, con la misma avidez de abismarse en lo profundo/misterioso:

La filosofía, fatigada de ese su largo paseo solitario que ha sido la época moderna, busca la compañía de la poesía, que es, de una manera u otra, la religión..$^{19}$

Sí, también el pensamiento filosófico tiene que abrirse a la profundidad de la vida - metafísica y religión-, más allá del cerco de las experiencias de superficie. De ahí que llegue a vaticinar que «la poesía como experiencia de la vida privada toca a su fin... se queda en poesía de la existencia y sólo a duras penas llega a ser poesía del ser», y se atreva a marcarle un nuevo rumbo: «una palabra mensajera de un mundo nuevo y vaticinadora de la plenitud del ser», ${ }^{20}$ aunque de inmediato le asalte la sospecha:

Yo no sé si es ésta la pocsía que tendremos. Desde luego, no es la que merecemos. Pero, al menos, creo que es la que necesitamos, la que nuestro tiempo demanda, la única que puede rescatarle.21 
Quizá la expresión más ajustada a la posición de Aranguren en la década del cuarenta y cinco al cincuenta y cinco sea la declaración contenida en El buen talante:

Si me fuera permitida - que no lo es- la ruptura de la unidad del espíritu, debería hablarse de un primado de la religión sobre la cultura. Pero la religión es también cultura, aunque no sea sólo cultura... La reducción a unidad de religión y filosofía es inadmisible; más ésto no empece a la primacía de la religión que, al establecer el orden y relación del hombre con respecto a Dios, y el sentido de la vida humana, delimita un ámbito cultural y una idea del hombre. ${ }^{22}$

He aquí el límite del reformador moral. Su mitigado racionalismo católico, basado en una metafísica fuertemente intelectualista como la de Zubiri, y su creencia, en fin, de la convergencia trascendental de lo ético, lo poético y lo religioso, definen una experiencia básica de la vida, que cofigure el espacio de juego de la reforma.

Fácilmente puede colegirse el profundo impacto que twvo que ocasionar la crisis en esta posición. Su afrontamiento con ella comienza en los primeros años de la década de los sesenta, recién concluida, como quien dice, su Ética —el libro más importante de filosofía moral española en lo que va de siglo-, pero escrito, a mi juicio, al margen de la crisis. Es justo reconocer, no obstante, que hay un momento en que la Ética toca el problema para dejarlo de lado como un abismo. Me refiero al tema del "ateísmo ético», posición negadora de toda trascendencia metafísica y religiosa en atención a "exculpar a Dios» y recabar la plena autonomía humana; una ética, en suma, trágica, desesperada, meramente formal o existencial, pero no por eso menos combativa. Un análisis estilístico del cap. XVIII de la Ética podría mostrar hasta qué punto el tema provoca a Aranguren y le produce ambiguamente fascinación y rechazo. El debate teórico con el problema es, a mi juicio, demasiado expeditivo en su desenlace, incluso en la forma misma de su refutación. Aranguren pretende volver del revés el ateísmo ético, al filo de la sentencia de Dostoievsky, mostrando sus graves consecuencias absurdas:

Pero si Dios ha muerto, si no existe ya, entonces la moral carece de fundamento y todo esta permitido... Pero si desaparece Dios, todo se torna relativo y puramente histórico, y sólo puede substituir la dimensión estructural de la moral, la moral formal del existencialismo, por ejemplo, pero no la moral como contenido, ${ }^{23}$

Una refutación, como se ve, excesivamente formal, trascendental mejor, como Aristóteles contra negantes principia, y que deja traslucir a las claras el escaso aprecio que tiene Aranguren por una ética formal, sea la kantiana o la existencialista, a las que precipitadamente pone 
del lado de la moral como estructura. ( ¿No están más cerca acaso de la moral como «actitud»?) En definitiva, todo el pasaje acusa el interés aranguriano en salvar una fundamentación normativa metafísica del contenido:

El ateísmo ético se reduce por tanto a sí mísmo al absurdo y, si es consecuente, tiene que desembocar en el derrocamiento nietzscheano de la moral, en el inmoralismo de André Gide, en la filosofía del absurdo de Camus, en el tremendo desorden moral de la filosofía de Sartre, en el nibilismo que denuncia Heidegger como signo de nuestro tiempo. ${ }^{24}$

$\mathrm{Y}$, sin embargo, en este signo de nuestro tiempo estaba el problema de fondo de la moral en una época de crisis. Unos años más tarde, con ocasión de su conferencia en Venecia, en 1962, sobre Implicaciones de la filosofia en la vida contemporánea (curiosamente en Venecia, y ante un auditorio europeo y dentro de un ciclo de problemas contemporáneos), el problema irrumpe con toda su fuerza y Aranguren no duda en llamarlo por su nombre de pila, nihilismo, con expresa referencia a Nietzsche, su profeta. Y de inmediato, como era de esperar, la mención inevitable a Heidegger:

Es, como ha hecho ver Heidegger, un acontecimiento epocal, por encima de la fe y la esperanza de muchos o pocos individuos, e implica con la negación histórica de Dios, la de todos los ideales, normas, principios y fines, es decir, la negación, en suma, de todos los valores que, hasta él, se alzaban por encima de los hombres, dando sentido a su vida... La nueva situación es bien descrita con la palabra "nihilismo». Nada de lo que daba sentido "sobrenatural" o "espiritual" a la existencia queda ya en pie. ${ }^{25}$

Se trata, pues, de una crisis principal, y por lo mismo, final, "extrema», es decir apocalíptica laica (=metafísica) de Occidente. Si en algunas ocasiones prefiere, sin embargo, calificarla de "desmoralización ${ }^{26}$ no le quita con ello un adarme de su gravedad; simplemente se limita a enfocarla desde la perspectiva de la experiencia moral (quiebra de códigos normativos y "pérdida de confianza en la empresa del quehacer colectivon), con su influjo destructivo en la actitud y la obra misma del ethos. Pero lo que se juega, en el fondo - y Aranguren lo sabe bien- es una crisis metafísica, y por tanto, de fundamentos y del horizonte de trascendencia de la existencia humana. La "crisis de los principios morales" expresa la más radical crisis de una razón de principios. Parafraseando una expresión suya, podría decirse que «a una vida sin fundamento corresponde, no sólo una ciencia, sino una ética sin fundamento». ${ }^{27}$

No voy a detenerme a analizar las diferentes posturas que presenta Aranguren ante la crisis, en su conferencia de Venecia. Sólo quiere alu- 
dir de pasada, que la desvalorización a que somete la llamada por él "moda ontológica" como salida de la crisis -en la que incluye, sorprendentemente, a N. Hartmann junto a Martin Heidegger-, tomándola como expresión de un talante reaccionario, conservadurista, ${ }^{28}$ le hurta, a mi juicio, la posibilidad de un sondeo más decisivo del nihilismo, pese a la referencia final, de indudable sabor heideggeriano, "a una realidad fabulosamente maquinizada, tecnificada y automatizada, producto de la segunda o tercera revolución industrial a que estamos asistiendo". ${ }^{29}$ Ante esta situación Aranguren parece alinearse con un pensamiento intelectualista de nuevo cuño, mitigado y de base fenomenológica que «tras el descombro del material derribado por la crisis», pueda acometer "la tarea inmediata" de la reconstrucción. ${ }^{30}$ No obstante, en medio de este panorama de filosofías ante la crisis no deja de hacer referencia al "poder del comunismo y el poder de la Iglesia católica». ${ }^{31}$ Al hilo de ella se comprende que en una obra posterior encare el vacío moral de la época desde esta doble perspectiva:

[...] o bien el cristianismo se reactualiza, vivifica y deja de estar al servicio de los intereses conservadores [...] o bien el mundo occidental tendrá que buscar otra solución. Esta solución moral puede venir por la vía de un neomarxismo crítico en Europa o por la de las problemáticas propuestas que surjan de la nueva izquierda americana o europea. ${ }^{32}$

Es el anuncio de dos ensayos gemelos, dedicados al final de los sesenta, a La Crisis del catolicismo (1969) y al El Marxismo como moral (1968). En ambos casos, la crisis, con la recesión de la metafísica, obliga a una autocrítica interna de consecuencias liberalizadoras: al catolicismo, liberado del corsé dogmático/metafísico y del paso de la autoridad doctrinal de la Iglesia, le abre la posibilidad de su autentificación existencial y moral y de apertura realmente ecuménica; y al marxismo, la posibilidad de ver su otra cara, cálida y humanista, moral, frente a las versiones metafísicas y estructurales dominantes. En suma, pone a los dos sobre un "terreno moral, en que cabe un diálogo entre ambos». ${ }^{33} \mathrm{Se}$ perfila así la idea de un "nuevo humanismo", que le rondaba desde comienzos de los sesenta, y al que prefiero llamar "humanitarismo", por su apertura realmente universal y su sentido ético y social frente a todo residuo de privilegio y discriminación, que genera fatalmente violencia:

El humanismo verdaderamente nuevo y verdaderamente humanitario será, pues, aquel que, por primera ver en la historia, luche, sin apelar a la violencia, contra casi todas las violencias: contra las violencias establecidas y contra las violencias que se quieran establecer. ${ }^{34}$ 
Dejando aparte si el nuevo humanismo, concebido ciertamente con anterioridad a la experiencia de las crisis, pero re-afirmado implícitamente en los dos ensayos gemelos, a los que acabo de hacer referencia, estaba o no a la altura de la circunstancia, lo que importa al caso es la conexión que establece Aranguren entre "crisis" y acontestación", y, claro está, con la liberación de un nuevo horizonte, ${ }^{35}$ y no sólo dentro del catolicismo, como es obvio, sino también en el otro continente ideológico con su otra «iglesia», su kerigma, su evangelio y su ortodoxia. Estos dos ensayos, más sociológico el dedicado al catolicismo y más hermenéutico el del marxismo, constituyen el último esfuerzo arangureniano por configurar una experiencia ético/religiosa, autocrítica y abierta, en medio de la crisis. Pero, al cabo, como era de esperar, la alternativa al nihilismo/desmoralización sólo podía venir de una inflexión decisiva en el planteamiento. Cerrada la posibilidad de atravesar el nihilismo, al modo heideggeriano, en una experiencia del límite interno del racionalismo, quedaba la posibilidad del «repliegue ético», como la llamară más tarde, "cuyo iniciador fue Kant, desde el contenido a la forma de la moralidad». ${ }^{36}$ En lugar de la metafísica, como justificación normativa, se abre ahora el doble polo de referencia de la experiencia moral: de un lado, el Faktum de la conciencia, como su foco irradiante, por lo que respecta a la forma misma de la moralidad; del otro complementariamente, por lo que atañe al contenido, el mundo de la vida, suelo último, también irrebasable, de la experiencia histórica del hombre. En la tensión de esta doble referencia, como entre los dos focos de una elipse, se constituye el campo, siempre problemático y por lo mismo abierto existencial e históricamente, de la experiencia moral. En congruencia con este giro, el estilo de la fundamentación deja paso al fragmentario y balbuciente de la orientación, más modesto y sobrio, pero también más convincente que el pretencioso normativo. Ya había señalado antes, en la conferencia veneciana, que ues al hilo de problemas concretos [...] como podrá accederse realmente, algún día, piecemeal, "pieza por pieza", según la expresión de Karl Popper, a una nueva y prudente metafísica . ${ }^{37}$ Análogamente, también en la arquitectura ética, hay que renunciar a la gran moral sistemática para centrar la atención en los minima moralia, expresión de Adorno que Aranguren hace suya, esto es, en las cuestiones morales concretas, en su relevancia inmediata y apremiante para la vida del hombre. Este cambio sustantivo de coordenadas no sólo tuvo repercusiones inmediatas en puntos centrales de su filosofía moral, como se verá, sino que inflexionó también, de modo decisivo, la tarea del reformador moral, al no contar ya con una base sólida de sustentación. 


\section{Actitud ética e intención utópica}

Conviene precisar, en primer término, qué alcance tiene el repliegue ético que propicia la crisis en el pensamiento arangureniano. Su Ética representa, sin duda, un paso decisivo sobre la moral vivida religiosa, en que se inscriben sus obras anteriores a 1958: formula una concepción autónoma de la ética de instancia religiosa, ${ }^{38}$ aun cuando abierta a ella, y fundada en lo esencial en un doble principio: el antropológico/estructural y el metafísico/normativo, en los que viene a recoger, puestas al día y reacuñadas con originalidad, las cuestiones clásicas del genus moris y el ordo boni respectivamente. Siguiendo a Zubiri, pero no menos a Ortega, como ha mostrado Bonete, Aranguren pone de manifiesto la estructura constitutivamente moral del hombre, en cuanto éste tiene que hacer su vida en una elección de posibilidades, ajustándose a la realidad y teniendo que justificar sus actos en este ajuste. "La justificación es pues la estructura interna del acto humano» - precisa Aranguren- y consiste en tener que "dar razón, pero no meramente explicativa [...] de la posibilidad que he puesto en juegon, ${ }^{39}$ esto es, de la pre-ferencia $y$, en general, del pro-yecto entero de la vida, en cuanto a su sentido. Péro, para dar cuenta de la altura moral de estas posibilidades es preciso recurrir a una regula morum, que no puede ser otra, puesto que se trata de ajustarse a la realidad, que el propio orden trascendental y categorial del bien, o de los bienes, en cuanto a fines de la acción humana. De ahí la oposición arangureniana -excesiva, a mi juicio, como luego se verá-, a una ética meramente formal como la kantiana, pues pierde de vista la dimension del ajustamiento, aparte de su moralismo puro, autosuficiente, del deber por el deber, al que contrapone, siguicndo de nucvo a Zubiri, la dimensión ontológica del bien como apropiando o exigitivo de realización. Más que obligación pura, propiamente dicha, el hombre está ob-ligado a la libertad, en cuanto es necesariamente libre y no puede renunciar a ella, sin presuponerla, y también ob-ligado a la felicidad, pues no puede dejar de apetecerla; y estos dos vínculos lo ob-ligan, a su vez, a la realidad, sustancia de lo posible y de lo deseable, y ámbito único en el que el hombre tiene que hacer su vida, su ethos, en suma, lo que merece la pena ser hecho con vistas a una vida libre relicitaria.

Así, el ethos, figura o configuración de la vida como un todo, si de un lado —desde la perspectiva de la libertad- es carácter o autoacuñación del sí mismo moral, desde la otra perspectiva de la felicidad, y en la medida en que la libertad está entretejida con el destino y el azar, es propiamente destinée (según Le Senne) ${ }^{40}$-ni mero destino ni destinación, sino mezcla de lo uno y de lo otro-, compromiso ético entre facticidad e idealidad, y, por tanto, felicidad en precario. El ethos es pues obra de la libertad en conjunción con el destino/providencia, y la felici- 
dad sería la vida lograda, saturada, en la consecución de su bien integral. Lo característico de la ética metafísica de Aranguren es el mantenimiento del vínculo interno entre libertad, bien y felicidad, de modo que por muy precario que pueda ser éste, no requiere una síntesis utópica, sino de la asistencia graciosa o gratuita (religión) para su cumplimiento. Moral, pues, abierta a la religión, pero no por modo postulatorio, sino ontológico, como la finitud está abierta e implantada en un orden que la trasciende. Ciertamente, la actitud ética no es la religiosa:

Entendemos por actitud ética el esfuerzo activo del hombre por ser justo, por implantar la justicia. Entendemos por actitud religiosa la entrega creyente, confiada y amorosa, a la gracia de Dios. ${ }^{41}$

Dicho en otros términos, si la ética desde el punto de vista estructural es justificación, la actitud ética, reduplicativamente, consiste en «demanda y exigencia», "en sentimiento de suficiencia» y autojustificación. ${ }^{42}$ Es pues de sentido inverso a la religiosa, pero puede ser complementaria de esta, tan pronto como el hombre asume su finitud, sin trampa ni autoengaño. (Ya vimos, sin embargo, que puede haber una finitud responsablemente asumida, que califique de autoengaño la apertura a la religión.) Pero el buen talante arangureniano de sentido católico, y una metafísica integradora zubiriana garantizan, cada uno a su modo, la conjunción entre lo poético/creativo, lo ético/realizativo - una creación condicionada por el talante, las circunstancias y el destino-, y lo religioso/consumativo. Al orden trascendental del ser corresponde así la armonía interior de la vida buena, que es también la vida bella y felicitaria.

Es de imaginar el efecto que tenía que producir en una posición tan complejamente armónica la experiencia de la crisis en su doble faz, metafísica y religiosa. Lo que se ponía en cuestión era precisamente este vínculo ontológico. Aparte de la influencia de la crisis pudiera haber tenido en el buen talante arangureniano, volviéndolo des-templado y agónico, en alguna medida, la tuvo, sin lugar a dudas, en su planteamiento normativo, que perdió su base de sustentación. En esta coyuntura, su ética tuvo que volverse "por necesidad" autónoma en un sentido muy afín al kantiano. En lo sucesivo, Aranguren propende a entender la metafísica, no como un sistema de respuestas, sino a lo sumo de preguntas que a la par que desbloquean la experiencia de su confinamiento positivo, le ayudan a su orientación práctica. De nuevo volvemos a hallarnos en la vecindad del kantismo. Sin introducir expresamente en su obra la dimensión de las «ideas» regulativas, creo que a esto vendría a reducirse en el segundo Aranguren, la economía de lo metafísico, a un ámbito pro-blemático -en el doble sentido de «hipotéticon y generativo de problemas-, y a la vez pro-yectivo o anticipativo de la ex-istencia. No se 
trata, según creo, de una metafísica residual, sino existencial, como $\mathrm{Na}$ turanlage. Desaparece, pues, en cuanto dimensión de fundamento/normativo del pro-yecto, pero no en la embocadura del mismo o pre-tensión utópica, que trasciende de continuo el ámbito de lo positivo. Incluso podría decirse que lo meta-físico se funde con el orden ético en cuanto exigencia de un tras-mundo o intra-mundo. Como apunta el propio Aranguren, "el repliegue interior» significa una vuelta a Kant, si no en la letra, al menos en la orientación. A falta de una sólida moral normativa en cuanto al contenido, se precisa retirarse al "fuero interno" y subrayar el Faktum moral. Se repite así un movimiento, que él mismo ha señalado como característico de épocas de crisis:

Pero como en el fondo no se sabe a qué atenerse con respecto a la intocable moral anterior, se produce el desplazamiento desde el plano de la realidad moral al plano de la conciencia moral. ${ }^{43}$

Claro está, que ahora se trata de una conciencia purgada de las ilusiones narcisistas y farisaicas por el rigor de la crisis, pero, al fin y al cabo, conciencia, ésto es, reconocimiento inmediato, no discursivo, del irrenunciable ser-moral. Ya en Moralidades de hoy de mañana (1973), que como su título indica es una reflexión ética sobre el texto abierto e histórico de la experiencia moral, se inicia este movimiento de anábasis hacia la conciencia, en sentido fuerte, como su-puesto y fuente de moralidad:

¿Qucda alguna posibilidad - se pregunta- de encontrar una base a la moral? En la noción, que acaba de ser muy rápidamente criticada, de "conciencia moral», algo parece haber de justo, aunque precario: la moral como Faktum $\left(\right.$ Kant) ${ }^{44}$

Y líneas más adelante señala que lo que le interesa en este Faktum no es tanto el contenido cuanto lo que hay en el de "postulado, la actitud moral». ${ }^{45}$ Creo que la expresión "postulado», muy equívoca en este contexto, de inspiración kantiana, debe entenderse en el sentido de una exigencia que constituye la forma misma de la moralidad. El refuerzo semántico que le presta el término "actitud" es el de la disposición subjetiva o resolución, propiamente moral, por tal exigencia incondicionada. Entre la moral como estructura y la moral como contenido hay, pues, un tercer sentido de moral como actitud, apenas destacado en la Ética y que ahora pasa a primer plano:

$\mathrm{Si}$, aunque sólo sea por un momento, distinguimos entre moral (estructura, forzosidad de tener que hacer - quehacer- la propia vida) y moral (precepto, deber de hacerla de una determinada forma), entonces hay que decir, volviendo a 
Kant, que lo único bueno sin limitación es la buena voluntad o, dicho con lenguaje más actual, la moralidad en tanto que moral como actitud. ${ }^{46}$

Como puede apreciarse, esto significa, junto a la estructura y el contenido, subrayar la forma misma de la moralidad o, si se prefiere, de la existencia moral en la acepción que Kant y Kierkegaard han dado a este término. No tanto qué debe hacer y qué debo hacer, sino cómo existir éticamente. Sobre el nivel de la estructura se precisa el acto, propiamente moral, de la elección o la resolución de "sí mismo" ante tal exigencia incondicionada. Aranguren rehuye el término «deber» por su sentido rigorista y descamado, y recurre a los de "postulado» y «actitud», pero en el fondo es innegable la inspiración kantiana del repliegue:

La actitud moral lo es siempre de exigencia y de autoexigencia, de used de justician, de búsqueda e inquietud, de inconformismo y crítica del código moral vigente que, por perfecto que parezca, es siempre perfectible, y de propuesta, a veces sólo balbuciente, de un orden moral mejor. ${ }^{4 ?}$

Y en cuanto «actitud» está mảs vertida al plano de la experimentación moral - desprendimiento irónico y trascendimiento utópico de la existencia moral en sí misma-, que al de la reflexión ética, aún cuando ambos sean indisociables.

Se comprende, por otra parte, que la «actitud ética» se perfile ahora en contraposición, no tanto a la uactitud religiosas, como a la sactitud estética" (Kierkegaard) del divertissment o la inerte y acomodaticia del instalado. Exigencia, pues, frente a inercia, aspiración frente a presión (Bergson), resolución frente a instalación satisfecha. Puede afirmarse que la exigencia moral envuelve una pretensión utópica, que mantiene la vida. Utopía, claro está, no en la acepción de pensamiento desiderativo, y por tanto visionario, sino en cuanto requerimiento incondicionado, inagotable e inteminable. Porque la utopía, o es actitud ética -crítica y anticipadora, experimentadora- o es simplemente desvario. El deber-ser origina siempre una tensión interna al orden del "ser", y sin embargo, o precisamente por cso, no es el "no-ser" sino el "poder-ser» más sccreto y originario, que podría desbloquear la realidad y abrirla on su horizonte más genuino de valor. El mundo moral es siempre, como vio Kant, un mundo nouménico o sustancia de libertad, aun en medio de todos los condícionamientos empíricos imaginables. Su exigencia actúa así como juicio crítico inmanente a la realidad y como partera de experiencias morales. Es, por tanto, reguladora, o más propiamente, inspiradora de moralidad.

El énfasis decisivo puesto en el Faktum moral inflcxiona también la temática ética, y en especial, el concepto central de ethos. En cuanto al 
carácter, antes que cuño conseguido o en vías de realización, es, en el sentido kantiano del término, prototipo ideal de la vida moral, y en consecuencia, vocación, no sólo como pro-yecto en vía, sino en el dinámico de pro-yección a lo incondicionado. Por lo que atañe a la felicidad, al no estar garantizada su vinculación ontológica, a priori, con la realización de la exigencia, queda también postulada como demanda utópica. La misma "vida moral" adquiere a esta luz una fisonomía más intensa y dramática, como autonarración cuyo argumento ha de ser in-ventado al filo mismo de la re-presentación, sin saber a ciencia cierta en que va a quedar la cosa. Es verdad que ya la Ética recogía esta perspectiva dramática de la vida moral como tiempo de in-vención y constitución:

Esta figura unitaria, mientras dura la vida, permanece siempre abierta y modificable. No sólo eso sino también "provisional», "indeterminada». Como decíamos antes, por ser la bondad objetiva, real y no pendiente simplemente de nuestra recta intención, nunca acabamos de saber, en esta vida, cual ha sido a punto fijo nuestro logro y nuestro malogro. ${ }^{48}$

Si, la vida moral es un texto vivo, y por tanto, dramático y abierto, como gusta recordar Aranguren en comparación a la literatura, pero si además se tiene en cuenta su esencial constitución utópica, la in-vención y realización de sí resulta una tarea ardua y siempre, siempre abierta, en la obra y en la intención, porque nadie puede estar en su secreto. De ahí la necesidad de que éste se nos revele algún día y nos de-vuelva la dimensión verdadera de lo que hemos debido ser. La utopía pide -esto es, postula, no exige- escatología, como revelación de su secreto. Muy unánimemente, la exigencia de sentido lo es también de comprensión:

Que se nos comprenda, esto es, no tanto que se nos juzgue como que se nos diga quiénes somos, quién soy; y que se nos scomprenda", ciña o abarque en una totalidad unitaria de inmarcesible sentido, la Deidad ante la cual hayamos existido, cuando menos como sueño; y que, si la vida es sueño, sea, haya sido, esté siendo, vaya a ser sueño de Dios.49

Pero, sobre todo -y es lo que conviene analizar ahora- este «repliegue ético" refuerza la postura del reformador moral. La actitud genera un dinamismo crítico/utópico inagotable como la misma exigencia. Se diría que el lugar que configuraba antes el ordo normativo se vuelve ahora más fluido y abierto, también más fragmentario y problemático:

La creencia (o el ethos) en la cual estamos, para poseer auténtico valor moral, ha de ser abierta y no dogmática, ha de dejar lugar para la aheterodoxia», para el inconformismo y la rebeldia..$^{50}$ 
Es decir, el auténtico valor moral reside en la actitud (existencia ética) con que se vive cada creencia o experiencia moral, en trance crítico/utópico, de desprendimiento y trascendimiento interior. $\mathrm{Y}$ es esta doble dimensión la que es ahora, en su tensión inmanente, productiva de moralidad: de un lado, hace operar el principio de negatividad crítica - de resistencia y oposición-, que disuelve toda moralidad in-suficiente desde el punto de vista de la actitud y del Faktum moral; del otro, la misma exigencia moral como guía utópica alumbra, a través de la crítica, como fermentando la propia experiencia, un nuevo y más alto horizonte de moralidad. Hay pues una relación dialéctica o circular entre ambas dimensiones. La pretensión utópica reobra sobre la dimensión crítica, profundizándola y orientándola con sus anticipaciones, y ésta, a su vez, fermenta de continuo la gestación simbólica de nuevos modelos de experimentación:

Esta segunda dimensión (la actitud moral) tiene un doble aspecto: la crítica del presente, de lo que se acepta porque «siempre ha sido asi" y "se da por supuesto" (lo que "taken for granted", que demandaba examinar Dewey), es decir, del código moral establecido, de los mores vigentes; y la creación del porvenir, aspecto en que aparece la función positiva de la utopía. ${ }^{51}$

La crítica de Aranguren se ciñe ahora a la moral establecida del consumismo - moral del bienestar y la utilidad-, que no deja florecer la exigencia propiamente ética, y a la cultura establecida, con su legitimación funcional omnímoda, inhibidora de toda disidencia; y a trasluz, deja entrever utópicamente un nuevo ethos de libertad, como resistencia del individuo autónomo frente al establishment, y sus presiones y tentaciones-, y también de la felicidad, sustentada sobre la paz interior, el des-prendimiento y la serenidad.

\section{Moralidad y eticidad}

Ya he indicado antes cómo el registro político apunta tímidamente en Catolicismo día tras día, dentro de la limitación propia de la circunstancia española. En este caso, sin embargo, la reflexión teórica - filosofía moral - se adelanta al ejercicio de la crítica, al menos de la escrita, pero no al compromiso político, porque conviene recordar de nuevo que Etica y Política aparece dos años antes de la separación de Aranguren de la Universidad por su participación y protagonismo en la contestación política universitaria contra el régimen franquista. Tan sólo unos años más tarde, Moral y Sociedad (1966) surge más ceñido al análisis de la moral social vivida, en este caso del XIX, incorporada a los usos sociales, instituciones y leyes, en una palabra, al ethos social. La expresión no es nue- 
va, sino que procede de la Ética, en correspondencia con el ethos personal. Alli defiende Aranguren una apertura de la ética individual a la social, en un sentido muy afín al aristotélico. Volviendo del revés el sociologismo, ve el hecho social como un hecho sustantivamente moral, con su propia figura o ethos --sistemas de valores y creencias-, en interrelación con la vida personal. También la sociedad necesita justificar sus reglas y relaciones de convivencia, y muy específicamente, recuerda al filo de A. Weber y $M$. Weber, que:

[...] el proceso civilizatorio-racionalizador, en virtud del cual hay una invencible tendencia a «ajustar» y ureajustar», es decir, justificar (por más que esta justificación nos parezca siempre discutible) modos de convivencia adoptados antes simplemente por tradición. ${ }^{52}$

El ethos social, así defînido, hace pensar inmediatamente en la Sittlichkeit hegeliana, como sustancia ética objetiva y vigente en el orden institucional. Éste es el tema central de Ética y Politica, donde la conjunción, vivida dramáticamente, pero por lo mismo pro-ductiva y hasta progresiva, de ambas órdenes marca claramente la diferencia con respecto a la posición integracionista y en cierto modo integrista de la Sittlichkeit en Hegel. En este sentido, Aranguren propone dos vías de moralización de la sociedad: de un lado, la relación interpersonal de alteridad, que por redundancia trasciende la moralidad intersubjetiva al cuerpo social en su conjunto; del otro, el plano impersonal de la aliedad u orden institucional, ${ }^{53}$ - distinción ésta, como se sabe, fundamental en el pensamiento ético/político arangureniano, la primera tiende a la conversión del «hombre privado en hombre público o ciudadano" ${ }^{54}$ en sus relaciones intersubjetivas y en sus virtudes cívicas; la segunda, a la conversión de las instituciones públicas, y en especial del Estado, en instituciones con sentido ético. Como especifica Aranguren:

[...] la moral no puede ser plenamente realizada al nivel colectivo más que por el Estado. La virtud sola, por muy social que sea, no basta ya para la producción de un orden objetivo justo..$^{55}$

Este segundo plano coincide con la Sittlichkeit (eticidad) hegeliana, en la medida en que supone una moralización institucional de los comportamientos sociales por obra de las instancias socioeconómicas y sociopolíticas de poder. Pero, a la vez, se trata ude una eticidad diferente a la hegeliana", como él mismo aclara, ${ }^{56}$ pues tiene un límite constitutivo en su propio carácter de sestablecimiento», es decir, es vida anónima y administración: 
Pero quede bien entendido que si el Estado, verbigratia, en tanto que Administración pública, asume tareas éticas, eo ipso, las administrativiza, las convierte en funciones técnicas. ${ }^{57}$

De ahí que, en contrapunto, es necesario el camino inverso de conversión de la moral pública en ethos personal y su reanimación constante desde las fuentes autónomas de la moralidad en el individuo. Como se ve, la rclación entre el ethos personal y el social es circular, en condicionamiento recíproco, pero el sentido de esta circulación es siempre personal, en cuanto que brota de la instancia individual y a ella ha de remitirse para cobrar su fuerza de motivación y convicción. Por decirlo en otros términos, la eticidad (Sittlichkeit) tiene que reanimarse y abrirse siempre de nuevo por la "moralidad" (Moralität kantiana). No obstante, Etica y Politica está escrito bajo el signo de una "moral de la responsabilidad" o de la realidad, como la llama Aranguren, ${ }^{58}$ con tono reivindicativo y constructivo, y hasta con ilusión -ilusión ética- a favor del ideal de un estado de justicia social y de plena y efectiva democratización. En la medida en que el planteamiento genérico es una ética de bienes -en este caso, el bien público o común o el orden justo de convivencia-, hace pensar en una concordancia, o convergencia, al menos, aunque abierta y perfectible, entre el ethos individual y el social. Aranguren se aparta así de una concepción trágica de la relación entre ética y política por otra de carácter dramático:

Comprensión dramática quiere decir afirmación de una compatibilidad ardua, siempre cuestionable, siempre problemática, de lo ético y lo político, fundada sobre una tensión de carácter más general: la de la vida moral como lucha moral, como tarea inacabable y no como instalación, de una vez por todas, en un statts de perfección..$^{59}$

Creo que la crisis afectó también a este orden de experiencia moral, haciendo ver hasta qué punto la tecnificación administrativa y burocrática de la moral social degeneraba en formas, no ya inertes, sino abiertamente restrictivas de la tensión moral. No es sólo cuestión de «inercia» y "marasmo". En cuanto institución de poder, el establishment genera, junto a la inercia, contención y restricción, y en esta medida, una grave clausura del discurso ético y el impulso moral. A mi parecer, el segundo Aranguren -si esta expresión no marca una ruptura profunda de supuestos-m, es decir, el Aranguren tras la crisis, es más sensible a admitir "la trágica ambigüedad moral de la política ${ }^{60}$ —expresión que él mismo aplica a Sartre y Merleau-Ponty-, y a detectar las formas pesantes, constrictivas, cuando no represivas, del establishment. Por así decirlo, descubre un límite interno a la moralización del poder. Esta es cierta- 
mente una tarea infinita, pero en un sentido utópico fuerte, en cuanto encierra una pretensión que no se deja realizar enteramente, y que, a la vez, genera en su realización resistencias y contrafiguras. De otra parte, el deslizamiento hacia la actitud ética con la polarización en el Faktum moral tenía que marcar el hiato constitutivo entre la exigencia moral de una generalización del bien o de los fines, sin limitación ni coacción, y las formas histórico/concretas, siempre limitadas y limitativas, de institucionalizar la moral; por el mismo hecho de tratarse de «institucionalización" ahora como indominable e insuperable, en contra del optimismo hegeliano de una Sittlichkeit, en que se reconcilian la libertad subjetiva y la necesidad moral objetiva, es decir, la identificación sustancial entre el deber ser y el ser. ${ }^{61}$

La vuelta a Kant, aunque sea matizado en su tono rigorista, pone el acento con más énfasis que nunca en la dimensión de la moralidad (Moralität), la instancia del Faktum moral y la conciencia autónoma, creadora de moralidad en su propia tensión de trascendencia, frente a la eticidad (Sittlichkeit), siempre administrada y establecida:

La actilud ética se desenvuelve en el plano del deber ser, deber ser que predicc opportune et inopportune, para criticar, desde él, el es político, contraponiéndolo, y para intentar sobreponer a éste y su realismo el idealismo de la razón utópica. ${ }^{62}$

El repliegue produce un desplazamiento del acento con respecto a Etica y Politica, pues Aranguren se muestra ahora «más propenso a la ética de la convicción que a la de la responsabilidad", y un cambio también del tono o del pathos, abiertamente ácrata, de intransigencia y contestación. No se trata sólo de "la progresiva moralización del código moral que encontramos vigente en nuestro grupon, ${ }^{63}$ sino de la resistencia y contestación a los «sistemas de eticidad» vigentes, en la medida en que contienen el cambio y la innovación. La cultura establecida no puede ser nunca una cultura crítica y progresiva, por muy abierta que se crea y que sea, incluso, en sus mecanismos institucionales. Al igual que la revolución permanente no puede institucionalizarse, la institucionalización política de la moral no se deja reformar fácilmente. De ahí que la revolución cultural ${ }^{64}$ permanente quede como la única salida - ¿trágica?, en cualquier caso, tensamente dramática- a la clausura del universo ético. Como reformador moral está de parte de una ética de la aspiración, en un tiempo de presión social y desarme de la imaginación y la conciencia.

Se comprende también el énfasis del segundo Aranguren en la democracia como utopía. Desde luego el tema no es nuevo. En Ética y Politica se defiende la "voluntad moral de democracia» en cuanto reanimadora incesante del sistema político: 
La democracia no es un status en el que pueda un pueblo cómodamente instalarse. Es una conquista ético-política de cada día, que sólo a través de una autocritica siempre vigilante puede mantenerse. Es más una aspiración que una posesión. Es, como decía Kant de la moral en general, una tarea infinita en la que, si no se progresa, se retrocede..$^{65}$

La mención a Kant es muy pertinente, porque permite reconocer el sentido utópico genuino, esto es, ético de esta aspiración. No es extraño que a vueltas con el tema, tras la experiencia de la crisis, se enfrente a la sociedad industrial avanzada con un ademán utópico. Es más: Aranguren es consciente de que este énfasis de hoy supone una corrección, en cierto modo, de la tipología de lo ético y lo político propuesta en 1966. Así, en Ética de la felicidad y otros lenguajes (1988) escribe:

Quisiera completar aquí aquella tipologia. Junto a la concepción cínica. trágica y dramática, cabe una concepción utópica de la política: concepción plenamente moral por verdaderamente democrática, de la política [...]. La utopía es el espíritu de la letra política y, como tal, tiene que penetrar de sentido a ésta. ${ }^{60}$

Frente, o mejor, sobre la democracia establecida, hay pues que situar, como su ideal y medida de juicio inmanente, la otra democracia in-establecida, y no obstante, requerida desde el mismo Faktum de la vida genérica, la democracia como «utopía moral», expresión muy justa porque el calificativo salva a la utopía de su perversión visionaria y de su tentación de violencia, y la inscribe en su verdadero lugar, que ciertamente no es de este mundo - del mundo establecido-, porque pertenece al orden de la exigencia moral:

Entiendo así la democracia, antes que como una forma política concreta, como la tarea -infinita - de democratización de la sociedad, de compromiso con ella, de engagement total [...].67

Obviamente, este poner en cuestión la eticidad (alicdad) vigente no es para suprimirla sino para reanimarla y ampliarla, y en todo caso, transformarla en la doble dirección de apertura a nuevos horizontes de valor y a nuevos impulsos renovadores. La función de esta utopía moral consistiría, pues, en constituirse en juicio crítico inmanente a la experiencia moral y política, y en su principio de orientación. En definítiva, eticidad y moralidad son dos dimensiones heterogéneas, que se cruzan sin jamás compenetrarse, ni en el sentido hegeliano de superación de la moralidad ni en el tecnoburocrático de disipación de la misma en el sistema del bienestar social. Y puesto que toda ética es siempre, como recuerda Aranguren, vida personal, la utopía moral de la democracia se 
integra, en cuanto a su condición de posibilidad, en la otra u-topia y u-cronía, porque penetra el tiempo y lo abarca en su conjunto, trascendiéndolo, que es el Faktum moral.

\section{Utopia y religión abierta}

A menudo utiliza Aranguren el giro «lo utópico/escatológico», no para confundir, sino para sobredeterminar la expresión y abrirla a una nueva referencia. $Y$, desde luego, aquí ha de verse el puerto de salida de la ética a la religión en el segundo Aranguren. Esto no supone renunciar a la temática de la "apertura", tal como fue expuesta en la Ética. Pero el punto de vista allí era diferente en la medida en que se partía de la contraposición de la actitud ética y religiosa, y se trataba, por consiguiente, de abrirse a la religión a través de la quiebra de la actitud arrogante e implícitamente a-tea del eticismo. Se entiende que el método fuera una reducción al absurdo del ateísmo ético, como expresión consumada del eticismo, y una exploración, a la vez, de la línea real de fractura o finitud en el comportamiento antropológico/moral. El valor de esta doble estrategia es muy desigual. Creo que la opción moral utópica, trágica y desesperada, como la del médico en $L a$ peste de Camus, no se deja reducir al absurdo ni refutar argüitiva o trascendentalmente, porque se refugia en el Faktum de la conciencia moral. Sólo en el supuesto de que la norma precise de una fundamentación metafísica podría argüirse que la negación de Dios arrastra consigo la del orden moral. El recurso a la experiencia moral -la impotencia, el fracaso, la frustracion-, y a aquellas situaciones límite en que el hombre afronta una necesidad más fuerte que sus pretensiones y esfuerzos denuncia, en cambio, una finitud inesquivable que no puede sustantivarse ni cerrarse sobre sí. ¿Es esto una objeción contra el Faktum moral? Realmente no, pero traduce una interna inadecuación o hiato entre el Faktum y su cumplimiento. ¿Cómo puede ser sometido a una exigencia incondicional un ente tan frágil y problemático? La respuesta kantiana ya se conoce: «puesto que debo, he de poder». Pero ¿verdaderamente puedo desde y por mí mismo? Realmente esto llevó a Kant a plantear una relación entre ética y religión de doble signo: no sólo a situar el stattss de la religión (en cuanto al contenido) dentro de los límites de la mera razón, sino a la recíproca, a poner el status de la moral (en cuanto a su cumplimiento) en el límite, aquí mejor frontera que contenedor, de la experiencia religiosa.

En su libro sobre la filosofía moral de Aranguren sostiene Bonete que éste no volvió a ocuparse del tema de la apertura de la ética a la religión. Explícita o expresamente, ciertamente no. Pero hay atisbos y 
apuntes que sin duda reabren el viejo tema a una nueva perspectiva. La mención del "postulado moral» que aparece en su obra tardía como sinónimo de la "actitud" y el Faktum moral hacen pensar en un planteamiento muy afín al kantiano. Como se recuerda, la ética kantiana se abría al ámbito religioso a través de los postulados de la razón práctica, como creencias exigitivas, implicadas, en cuanto condiciones de viabilidad de la praxís moral. Sospecho que es ésta la línea de apertura a la que propende el segundo Aranguren. La actitud ética se abre a la religiosa, porque, en cuanto utopía no puede renunciar a la «necesidad subjetiva» de mantenerse en la esperanza, y en una esperanza abierta e improgramable, esto es, en una esperanza que desborda todo proyecto histórico de realización. Es, por así decirlo, la misma inadecuación o hiato entre exigencia ideal y orden fáctico/temporal lo que alienta una esperanza escatológica, en el sentido fuerte de la expresión. Esta salida se muestra, por otra parte, congruente con el propio planteamiento del problema. Tras la crisis, acentúa Aranguren, como vamos viendo, una moral abierta, en sentido bergsoniano, de tensión y aspiración, in-ventiva o creativa, con élan moral reformador, capaz de promover una sociedad abierta y progresiva, ${ }^{68}$ como contrapunto a la clausura del universo político/tecnológico de la sociedad de bienestar. Ahora bien,

[...] la verdadera creación busca la recuperación del mito y el símbolo, y se entrega totalmente a la tarea de decir lo indecible. ${ }^{69}$

Y este ámbito de lo indecible, de lo propiamente místico, donde la imaginación creadora hunde sus raíces en busca de sus arquetipos, es también el ámbito de lo in-programable e in-decible, de lo sencillamente gratuito. En él la poesía se hermana de nuevo con la religión.

Se diría que en Aranguren la moral abierta se encuentra ya desde el comienzo, desde su inspiración misma, desfondada o abierta hacia la experiencia religiosa. En Eugenio d'Ors y en Juan de la Cruz, a los que dedica sus primicias como escritor, había encontrado J.L. Aranguren, al comienzo mismo de su aventura ética —es verdad que con muy distintos acordes-, el lema religio est libertas, porque la experiencia de la libertad, ésto es, del poder activo y creativo del hombre, en cuanto acto i-limitado y de pretensión absoluta, sobrenada en el misterio. Por eso, cuando la libertad olvida su secreto de implantación, tiende a sustantivarse como ab-soluta y a despeñarse en una utopía compulsiva, que no puede dejar de desencadenar violencia, porque cree que le asiste toda la razón. Pero toda la razón no está en ninguna parte, en ningún tiempo, en ningún solitario corazón. Toda la razón, como toda la felicidad, es tan sólo una exigencia que impulsa y sostiene a tergo la libertad del hombre. Creo que el segundo Aranguren, heterodoxo y con oscuros presentimientos utópi- 
cos/místicos en algún secreto rincón de su alma, cree en esta religión de la libertad, que es lucha y búsqueda, como ya había indicado Unamuno, pero también esperanza para no dimitir. La moral abierta, utópica, se acompasa así con una religión de la confianza.

En su obra sobre Aranguren, analítica y rigurosa, apunta Enrique Bonete en un par de ocasiones cierta afinidad de la actitud de Aranguren con los francfortianos, especialmente en la doble faceta crítico/utópica del intelectual. ${ }^{70}$ Como tantas otras sugerencias de Bonete, esta me parece sumamente interesante. Creo que puede dar la clave de la evolución y tensión interna de la obra arangureniana. Porque, en efecto, hay mucho del espíritu del tiempo y sus avatares que comparte José Luis Aranguren con dos francfortianos de la segunda generación: Horkheimer y Adorno, y en alguna medida, con H. Marcuse, exiliados -autoexiliado Aranguren- de regímenes autoritarios en América y vueltos de la experiencia americana, desengañados o desencantados, pero con la firme resolución de resistirse en una postura crítico/utópica. El paralelismo entre Horkheimer y Aranguren podría rastrearse en la misma evolución interna desde una posición canónica inicial - ya sea en el marxismo humanista o en el catolicismo liberal respectivamente- a una experiencia de la crisis, igualmente áspera y profunda, que acaba afectando a la credibilidad de los dos sistemas establecidos -el liberal-americano y el socialismo de Estado soviético-, (al igual que en Marcuse); y de allí al repliegue, en la vuelta a Kant y hacia la ética del individuo autónomo, una ética de resistencia y contestación, pero también, bajo el principio de la utopía. Con Adorno comparte Aranguren su tendencia a ejercer la crítica a modo de dialéctica negativa, que convierte la experiencia del dolor en un medio de experimentación, y su preferencia por la mínima moralia, y acaso con Marcuse, el haber encarnado para la juventud española la figura de un emancipador - autoemancipador como conviene a un moralista de ley-, que va por delante abriendo caminos y despejando horizontes. Pensadores utópicos todos ellos, que creen, por decirlo con Adorno, que «la verdad es la esperanza». Utopía a la que preserva de caer en la tragedia el propio vuelo de la esperanza, para un camino, que no es enrancia, como pudiera parecer, sino experimentación:

Desembocamos en los éxtasis del tiempo, en nuestra necesidad de vivir escatológicamente, fuera del presente, en el recuerdo o en la esperanza, en mi caso y pese a mi vejez, más todavía en el futuro que en el pasado; pero siempre, y éste es el único vagabundeo que me queda, siempre en ningún Dónde real, sino allí donde confinan Arcadia y Utopía. ${ }^{7}$ 


\section{NOTAS}

1. Miguel de Unamuno, Obras completas, Madrid, Escelicer, 1967, VI, 900.

2. Ibidem, I, 1.178 .

3. Enrique Bonete, Aranguren: la Etica entre la religion y la politica, Madrid, Tecnos, 1989, pp. $29-30$.

4. José Luis Abellán, "Introducción» a la edición de J.L. Aranguren, La Filosofía de Eugenio dOrs, Madrid, Espasa-Calpe, 1981, p. 15.

5. J.L. Aranguren, Contralectura del Catolicismo, edición comentada de Catolicismo día tras dia, Barcelona, Planeta, 1978, p. 195.

6. Ibid., pp. 63.64 .

7. Norbert Bilbeny, aAranguren: estructura y coyuntura», El Cieno (Barcelona), 468 , febrero (1990), p. 12.

8. Etica, Madrid, Revista de Occidente, 1958, p. 11.

9. Ibid., p. 421.

10. Eugenio d'Ors, La Filosofia del hombre que trabaja y que juega, Montevideo, Artigas, p. 39 .

11. J.L. Abellán, «Introducción", art. cit., p. 27.

12. J.L. Aranguren, La Cuitura española y la cuitura establecida, Madrid, Taurus, 1975, p. 236.

13. Ibid., pp. 228-229.

14. Contralectura del Catolicismo, op. cit,, p. 64.

15. Ibid., p. 14.

16. Ibid., p. 64.

17. Ibid., p. 191

18. Crítica y Meditación, Taurus, Madrid, 1957, p. 26.

19. Ibid., p. 67.

20. Ibid., p. 77 .

21. Ibid., p. 77 .

22. El buen talante. Madrid, Tecnos, 1985, p. 37.

23. Ética, op. cit., p. 162.

24. Ibid., p. 163.

25. Implicaciones de la flosofia en la vida contemporánea, Madrid, Cuadernos Taurus, 1971, p. 26.

26. Proptestas morales, Madrid, Tecnos, 1984, p. 124,

27. Apud E. Bonete, op. cit., p. 224.

28. Implicaciones..., op. cit., pp. 38-39.

29. Ibid., p. 70 .

30. Ibid., p. 66 .

31. Ibid. p. 49.

32. Propuestas morates, op. cit., p. 105.

33. El Marxismo como moral, Madrid, Alianza editorial, 1968, p. 164.

34. E. Bonete, op. cit., p. 260.

35. La Crisis del catolicismo, Madrid, Alianza Editorial, 1969, p. 182.

36. Propuestas morales, epllogo del 84 , op. cit., p. 129.

37. Implicaciones..., op. cit., p. 63.

38. No puedo compartir, por eso, la tesis de E. Bonete de que Aranguren tiene en su Eica un punto de partida religioso-católico (op. cit., p. 197), salvo que entienda por esto una inspiración básicamente religiosa de su planteamiento.

39. Etica, op. cit., p. 65.

40. Ibid., p. 170.

41. Ibid., p. 142

42. lbid., p. 142 . 
43. Ética de la felicidad y otros lenguajes, Madrid, Tecnos, 1988, p. 107.

44. Moralidades..., op. cit., p. 164.

45. Ibid, p. 145.

46. Propuestas morales, op. cit., pp. 129-130.

47. Ética de la felicidad..., op. cit., p. 111.

48. Etica, op. cit., p. 397.

49. Moral de la vida cotidiana, personal y religiosa, Madrid, Tecnos, 1987, p. 69 .

50. Ibid, p. 68.

51. Moralidades..., op. cit., pp. 166-167.

52. Ética, op. cit., p. 399.

53. Etica y Polftica, Madrid, Guadarrama, 1963, p. 141.

54. Ibid, p. 178.

55. Ibid, pp. 267-268.

56. Memorias y esperanzas espanolas, Madrid, Taurus, 1969, p. 148.

57. Etica y Politica, op. cit., p. 268.

58. Ibid, p. 26.

59. Ibid., p. 123.

60. Ibid, p. 117 .

61. Hegel, Enciclopedia, pr. 514.

62. Etica de la felicidad..., op. cit., p. 129.

63. Propuestas morales, op cit., p. 73.

64. Ética de la felicidad..., op. cit., pp. 120-121

65. Etica y politica, op. cit. p. 188.

66. Ética de la felicidad..., op. cit., p. 91.

67. Ibid, p. 117.

68. Moratidades..., op. cit., pp. 165-166.

69. Ibid., p. 194.

70. E. Bonete, op. cit, p. 239, nota 41.

71. J.L. Aranguren, Epílogo al libro de Enrique Bonete, Aranguren: La ética entre la religión y la política, Madrid, Tecnos, 1989, p. 348 